\title{
The Impact of Language Barriers on Documentation of Informed Consent at a Hospital with On-Site Interpreter Services
}

\author{
Yael Schenker, $\mathrm{MD}^{7}$, Frances Wang, $\mathrm{MS}^{7}$, Sarah Jane Selig, $\mathrm{BS}^{7}$, Rita $\mathrm{Ng}, \mathrm{MD}^{7}$, \\ and Alicia Fernandez, $M D^{1,2}$ \\ 'Department of Medicine, University of California, San Francisco, CA, USA; ${ }^{2}$ Clinical Medicine, University of California, San Francisco, \\ CA, USA.
}

BACKGROUND: Informed consent is legally and ethically required before invasive non-emergent procedures. Language barriers make obtaining informed consent more complex.

OBJECTIVE: Determine the impact of language barriers on documentation of informed consent among patients in a teaching hospital with on-site interpreter services.

DESIGN: Matched retrospective chart review study.

SUBJECTS: Eligible Chinese- and Spanish-speaking patients with limited English proficiency (LEP) who received a thoracentesis, paracentesis, or lumbar puncture were matched with eligible English-speaking patients by procedure, hospital service, and date of procedure.

MEASUREMENTS: Charts were reviewed for documentation of informed consent (IC), including a procedure note documenting an IC discussion and a signed consent form. For LEP patients, full documentation of informed consent also included evidence of interpretation, or a consent form in the patient's primary language.

RESULTS: Seventy-four procedures in LEP patients were matched with 74 procedures in English speakers. Charts of English-speaking patients were more likely than those of LEP patients to contain full documentation of informed consent ( $53 \%$ vs $28 \%$; odds ratio (OR): 2.81; 95\% CI, 1.42-5.56; $p=0.003)$. Upon multivariate analysis adjusting for patient and service factors, English speakers remained more likely than LEP patients to have full documentation of informed consent (Adj OR: 3.10; 95\% CI, 1.49-6.47; $p=0.003$ ). When examining the components of informed consent, charts of English-speaking and LEP patients were similar in the proportion documenting a consent discussion; however, charts of English speakers were more likely to contain a signed consent form in any language (85\% vs $70 \%, p=0.03)$.

CONCLUSIONS: Despite the availability of on-site professional interpreter services, hospitalized patients who do not speak English are less likely to have documentation of informed consent for common invasive procedures. Hospital quality initiatives should consider monitoring informed consent for LEP patients.
KEY WORDS: language barriers; informed consent; health care disparities; limited English proficiency; Spanish; Chinese; interpreter use.

J Gen Intern Med 22(Suppl 2):294-9

DOI: $10.1007 / \mathrm{s} 11606-007-0359-1$

(C) Society of General Internal Medicine 2007

\section{BACKGROUND}

Informed consent . . . is ethically required of healthcare practitioners in their relationships with all patients, not a luxury for a few. ${ }^{1}$

Informed consent is central to the practice of ethical, safe, legal, and patient-centered health care. Defined as "voluntary consent given by a person or a responsible proxy (e.g., parent) for participation in a study, immunization program, treatment regimen, invasive procedure, etc., after being informed of the purpose, methods, procedures, benefits and risks," ${ }^{2}$ informed consent is a process of information exchange that by its very nature requires dialog between patient and provider. ${ }^{3,4}$ When patient and provider speak different languages the process of informed consent necessarily becomes more complex, as the informed consent discussion must be conducted either in a language the patient understands, or through an interpreter.

The population of the United States is growing linguistically more diverse each year, with approximately 11 million people reporting they speak English "not well" or "not at all" in the 2000 U.S. census. ${ }^{5}$ Language barriers have been found to complicate many aspects of patient care, ${ }^{6}$ including receipt of medical services, ${ }^{7}$ patient satisfaction, ${ }^{8-10}$ interpersonal processes of care, ${ }^{11}$ comprehension, ${ }^{12,13}$ adherence to prescribed medication regimens, ${ }^{14}$ and length of hospital stay. ${ }^{15}$ Advocates for patients with limited English proficiency (LEP) have searched for ways to make interpreters available to patients who need them and to make LEP patients aware of their rights to an interpreter. ${ }^{16}$ To date, most patients and providers do not have access to professional interpreters, ${ }^{13}$ yet a body of research suggests that interpreters may be underutilized even when readily available. ${ }^{12,17-19}$

Recognizing the importance of communication to informed consent, we designed a study to compare informed consent documentation for common invasive medical procedures between LEP and English-speaking patients at a large public teaching hospital with interpreters on site. Documentation of informed consent is required at this hospital and at most 
hospitals in the United States and is a legal standard by which to judge whether informed consent has taken place.

\section{METHODS}

\section{Setting}

The study was conducted at a public teaching hospital serving the city and county of San Francisco. The county has a large immigrant population; approximately $20 \%$ of patients do not speak English, and more than 20 languages are spoken within the hospital each month. The hospital has received several national awards recognizing the depth and quality of its interpreter services. Interpreter services are available on-site for 19 languages through professional staff interpreters, with a total of 25 languages available with prearrangement through an "on-call" system of interpreters. ${ }^{20}$ The Interpreter Services Department provides on-site interpreters 16 hours a day, 7 days a week. The hospital also subscribes to a commercially available telephone interpreter service that can be accessed through any bedside phone, at any time. Standard consent forms for bed-side procedures, with blank spaces to insert the type of procedure, common risks, and alternative treatments, are available on the hospital wards and in the emergency department in 5 languages, including English, Spanish, and Chinese. The hospital is staffed by house officers from the University of California, San Francisco residency programs, and almost all procedures are performed by residents. The university institutional review board and the hospital data governance board approved the study.

\section{Subjects}

This was a matched retrospective chart review study. Study participants were selected through a search of an electronic administrative/clinical database by ICD-9 code. Adult patients who received a lumbar puncture (03.31), thoracentesis (34.91), or paracentesis (54.91) while hospitalized between January 1, 2004 and January 1, 2006 were potentially eligible. All patients whose language field in the dataset identified the patient as speaking either "Spanish" or "Cantonese/Chinese/ Mandarin" were assigned to the LEP group, whereas those whose language field was "English" were assigned to the English group. Reasoning that hospital service and secular trends with respect to work load could influence consent procedures and the adequacy of documentation of these procedures, we matched LEP and English-speaking patients by: 1) procedure, 2) medical service on which the patient was hospitalized (medicine, neurology, or family practice), and 3) the month the procedure occurred. A list of potential Englishspeaking matches was generated for each LEP patient; the closest eligible match was chosen.

\section{Data Collection}

Medical charts were reviewed for each potential study participant. Information on patient gender, language, race/ethnicity, age, and medical service was abstracted from the hospital's electronic administrative/clinical database. Date of admission, date of discharge, and primary diagnosis at discharge were obtained from an administrative coversheet in the paper chart summarizing each admission.

All pages of the medical chart during the admission period were searched for evidence of a procedure note and a consent form. If a procedure note was identified, it was reviewed for documentation of the following: informed consent obtained (yes/no), patient unable to participate in informed consent (yes/no, reason for inability to participate in informed consent), informed consent obtained from family member (yes/ no), informed consent obtained in patient's language (yes/no), and interpreter used (yes/no). If a standard consent form was identified, we abstracted the following: language in which the form was written (English, Spanish, or Chinese), relationship of the person signing the form (patient or surrogate), and presence of an interpreter signature on the form.

Fifteen percent of the medical charts were randomly selected and reabstracted by an investigator blinded to the study hypothesis. Reabstraction demonstrated excellent agreement on comparison of informed consent (kappa coefficient $=0.83$; 95\% CI, 0.60-1.00). To verify that the patient's language was as given in the electronic dataset, the same charts were also searched for documentation of the patient's primary language. Confirmation of primary language was found in the visit notes of $75 \%$ of LEP patient charts.

\section{Eligibility}

After review of the medical chart, patients who lacked health care decision-making capacity at the time of the procedure were excluded. Patients were determined to lack health care decision-making capacity if the procedure note or progress notes on the day of the procedure included documentation that the patient was unable to participate in informed consent for any clinical reason or indicated that the patient had altered mental status. We also excluded patients on mechanical ventilation at the time of the procedure and patients whose consent form was signed by a surrogate. Finally, we excluded patients whose procedure was performed by the interventional radiology service or in the operating room, as these services have a separate process for obtaining informed consent.

\section{Documentation of Informed Consent}

We defined full documentation of informed consent using the hospital's policy on informed consent documentation. This policy is based on commonly applied legal standards and on the principle of informed consent as a process requiring dialog. ${ }^{21}$

Full documentation of informed consent required a procedure note documenting a consent discussion and a signed consent form. For LEP patients, full documentation additionally required some evidence of interpretation. Acceptable evidence of interpretation included 1 or more of the following: 1) documentation in the procedure note of a consent discussion in the patient's language or through an interpreter; 2) a consent form written in the patient's primary language; or 3) an interpreter's signature on the consent form.

\section{Analysis Plan}

We used chi-square analysis to determine differences in informed consent documentation between procedures per- 
formed on LEP and English-speaking patients. To further refine our understanding of these differences, we used multivariate analysis to determine the independent contribution of patient factors (age, gender, primary language, and primary diagnosis) and health care factors (procedure and setting [ED vs wards]) to informed consent.

\section{RESULTS}

One hundred forty-six LEP patients were identified who had 187 procedures. Seventy-four procedures were excluded, leaving 113 eligible procedures in 92 patients. Reasons for exclusion were: medical records not available (9), documented altered mental status (14), consent form signed by a surrogate (12), patient intubated (9), procedure performed by interventional radiology or in the operating room (25), and wrong procedure coded (5). A total of 156 charts of potential English-speaking matches were reviewed. Eighty-two procedures in English speakers were excluded for the following reasons: documented altered mental status (28), consent form signed by a surrogate (16), patient intubated (17), procedure performed by interventional radiology (10), wrong procedure coded (4), and duplicate match found (7). Of the 92 LEP patients, eligible Englishspeaking matches were found for 74 procedures in 70 LEP patients, and these constitute our study sample.

Table 1 shows the characteristics of the patients and procedures. LEP and English-speaking patients did not differ by age or diagnosis, but English speakers were more likely to be male $(78 \%$ vs $59 \%, p=0.01)$. The LEP population was $69 \%$ Latino and $31 \%$ Asian, whereas the English speakers were of diverse races. The majority of procedures were performed while patients were hospitalized on a Medicine service (54\%), followed by the Emergency Department (28\%) and Neurology or Family Practice (18\%). Most patients underwent procedures related to a primary diagnosis of infection (41\%) or malignancy

Table 1. Characteristics of Patients Undergoing Invasive Procedures by English Proficiency

\begin{tabular}{|c|c|c|c|}
\hline & LEP* & English-Speaking & $p$ value \\
\hline & $(n=74)$ & $(n=74)$ & \\
\hline Mean Age $\pm \mathrm{SD}$, years & $50 \pm 16$ & $47 \pm 12$ & 0.3 \\
\hline Male $N(\%)$ & 44 (59) & $58(78)$ & 0.01 \\
\hline Race $N(\%)$ & & & $<0.001$ \\
\hline White & & $28(38)$ & \\
\hline Black & & 26 (35) & \\
\hline Latino & $51(69)$ & $10(14)$ & \\
\hline Asian & $23(31)$ & $10(14)$ & \\
\hline Medical Service $N(\%)$ & & & 0.9 \\
\hline Medicine & $41(55)$ & 39 (53) & \\
\hline Emergency Department & $21(28)$ & $21(28)$ & \\
\hline Neurology/Family Practice & $12(16)$ & 14 (19) & \\
\hline Diagnosis $N(\%)$ & & & 0.5 \\
\hline Infection & 29 (39) & $32(43)$ & \\
\hline Malignancy & $12(16)$ & $7(9)$ & \\
\hline Other & $33(45)$ & $35(47)$ & \\
\hline Procedure $N(\%)$ & & & 1 \\
\hline Lumbar puncture & 40 (54) & $40(54)$ & \\
\hline Thoracentesis & $10(14)$ & $10(14)$ & \\
\hline Paracentesis & $24(32)$ & $24(32)$ & \\
\hline
\end{tabular}

*LEP_Limited English Proficiency
Table 2. Rates of Informed Consent Documentation for Invasive Procedures in LEP* and English-Speaking Patients

\begin{tabular}{|c|c|c|c|}
\hline & LEP & $\begin{array}{l}\text { English- } \\
\text { Speaking }\end{array}$ & $p$ value \\
\hline & $\begin{array}{l}(n=74) \\
N(\%)\end{array}$ & $\begin{array}{l}(n=74) \\
N(\%)\end{array}$ & \\
\hline A. Procedure note & $66(89)$ & $64(86)$ & 0.6 \\
\hline $\begin{array}{l}\text { B. Procedure note documentation of } \\
\text { informed consent discussion }\end{array}$ & 44 (59) & $43(58)$ & 0.9 \\
\hline $\begin{array}{l}\text { C. Procedure note documentation of } \\
\text { informed consent discussion in } \\
\text { patient's primary language or } \\
\text { through an interpreter }\end{array}$ & $5(7)$ & N/A & \\
\hline D. Consent form-any language & $52(70)$ & $63(85)$ & 0.03 \\
\hline $\begin{array}{l}\text { E. Consent form-patient's } \\
\text { language or signed by an } \\
\text { interpreter }\end{array}$ & $30(41)$ & $63(85)$ & $<0.0001$ \\
\hline $\begin{array}{l}\text { F. Procedure note documentation of } \\
\text { informed consent discussion }+ \\
\text { consent form-any language }(B+D)\end{array}$ & $40(54)$ & 39 (53) & 0.9 \\
\hline $\begin{array}{l}\text { G. Full documentation of informed } \\
\text { consent (including evidence of } \\
\text { interpretation for LEP patients) } \\
(\mathrm{B}+\mathrm{E} \text { or } \mathrm{C}+\mathrm{D})\end{array}$ & $21(28)$ & $39(53)$ & 0.003 \\
\hline
\end{tabular}

(13\%). Slightly more than half $(54 \%)$ of procedures were lumbar punctures.

English-speaking patients were significantly more likely than LEP patients to have full documentation of informed consent (including evidence of interpretation for LEP patients) (53\% vs 28\%, OR: $2.81 ; 95 \%$ CI, 1.42-5.56; $p=0.003)$. When the components of informed consent documentation were examined (Table 2), English speakers and LEP patients did not differ by whether a procedure note was present in the chart $(86 \%$ vs $89 \%$, $p=0.6$ ) or by whether the procedure note reported an informed consent discussion ( $58 \%$ vs $59 \%, p=0.9$ ). However, English speakers were more likely than LEP patients to have a consent form (in any language) in the chart ( $85 \%$ vs $70 \%, p=0.03$ ). Further, only $41 \%$ of LEP patients had a consent form in their primary language or signed by an interpreter. Involvement of an interpreter was documented for similar numbers of Chinese-speaking and Spanish-speaking patients ( $22 \%$ vs $29 \%, p=0.5$; data not shown).

In a multivariate analysis, adjusting for patient age, gender, primary diagnosis, procedure type, or medical service did not significantly alter the results (Table 3). Language was the only factor significantly associated with documentation of informed consent.

Race was not included in the multivariate analysis as the overlap between race and language in the LEP group did not allow us to analyze their independent contributions. We found no differences in documentation of informed consent among English speakers when the analysis was stratified by race, and in the LEP group, we found no difference between Chineseand Spanish-speaking patients (39\% vs 23\%; OR: 2.09 ; $95 \%$ CI, 0.73-6.02; $p=0.17$ ).

\section{DISCUSSION}

To our knowledge, this is the first study to investigate the impact of language barriers on informed consent documenta- 
Table 3. Independent Predictors of Informed Consent Documentation for Invasive Procedures in LEP* and English-speaking Patients

\begin{tabular}{|c|c|c|c|c|}
\hline & \multicolumn{2}{|c|}{ Consent Form-Any Language } & \multicolumn{2}{|c|}{ Full Documentation of Informed Consent } \\
\hline & Unadjusted & Adjusted & Unadjusted & Adjusted \\
\hline \multicolumn{5}{|l|}{ Language } \\
\hline English & $2.42(1.08-5.46)$ & $2.82(1.15-6.92)$ & $2.81(1.42-5.56)$ & $3.10(1.49-6.47)$ \\
\hline LEP & Ref & & & \\
\hline Age & $1.00(0.97-1.03)$ & $0.97(0.94-1.01)$ & $1.02(0.99-1.04)$ & $1.03(1.00-1.06)$ \\
\hline \multicolumn{5}{|l|}{ Gender } \\
\hline Female & $1.27(0.53-2.99)$ & $1.69(0.59-4.78)$ & $0.70(0.34-1.45)$ & $0.66(0.29-1.51)$ \\
\hline Male & Ref & & & \\
\hline \multicolumn{5}{|l|}{ Diagnosis } \\
\hline Infection & $0.51(0.22-1.18)$ & $0.44(0.17-1.16)$ & $0.99(0.49-2.00)$ & $0.94(0.41-2.15)$ \\
\hline Malignancy & $1.14(0.29-4.55)$ & $1.00(0.23-4.38)$ & $1.37(0.49-3.80)$ & $1.53(0.50-4.71)$ \\
\hline Other & Ref & & & \\
\hline \multicolumn{5}{|l|}{ Procedure } \\
\hline Lumbar Puncture & $0.75(0.22-2.51)$ & $1.44(0.35-6.01)$ & $1.05(0.39-2.86)$ & $1.98(0.60-6.49)$ \\
\hline Paracentesis & $1.08(0.29-4.03)$ & $1.23(0.31-4.89)$ & $0.98(0.34-2.85)$ & $1.08(0.34-3.37)$ \\
\hline Thoracentesis & Ref & & & \\
\hline \multicolumn{5}{|l|}{ Medical Service } \\
\hline E.D. & $0.26(0.12-0.59)$ & $0.18(0.07-0.49)$ & $0.48(0.22-1.05)$ & $0.49(0.21-1.17)$ \\
\hline Wards & Ref & & & \\
\hline
\end{tabular}

Figure represent odds ratios (95\% confidence intervals).

*LEP—Limited English Proficiency

tion in a clinical setting. We found that patients who spoke English were almost twice as likely as patients with limited English proficiency to have documentation of informed consent for 3 invasive medical procedures while hospitalized at a large urban hospital with on-site interpreter services. The relationship between primary language and informed consent documentation was not affected by patient age, gender, primary diagnosis, procedure, or medical service.

The differences we found in rates of informed consent documentation between LEP and English-speaking patients are substantial and suggest disparities in the process of informed consent. Whereas it is possible that failure to properly document evidence of interpretation when obtaining consent from LEP patients may partially explain our results, the finding that LEP patients were significantly less likely than English-speakers to have a consent form present in the chartin any language-suggests that differences in practice, not documentation alone, drive our findings.

We also found low rates of documented informed consent for English-speaking patients. Whereas adequate documentation may not reflect the quality of an informed consent discussion, short of direct observation it remains the only way to judge whether such a discussion occurred. Informed consent documentation is therefore dictated by hospital policy and the law. Our findings for English-speaking patients highlight a need for increased training of resident physicians in the legal and ethical requirements of informed consent and informed consent documentation for all patients.

Despite Federal and State law requiring providers to use interpreters ${ }^{22,23}$ and this hospital's policy that interpreter use be documented in the patient's medical record ${ }^{21}$ fewer than a third of LEP patients had documentation of interpreter involvement in the process of informed consent. It is important to consider all possible explanations for these findings, as many factors may be involved. Because we did not measure language ability directly, it is possible that some of the patients classified as LEP may understand and speak sufficient English to participate in the process of informed consent without the services of an interpreter. Another possibility is that residents may be relying on their own language skills to consent patients and neglecting to document this in the chart. However, whereas more residents at this institution speak Spanish than Cantonese or Mandarin ${ }^{18}$, we found similar rates of documented interpreter use between the groups, suggesting that use of resident language skills do not entirely account for our findings. A third possible explanation is the undocumented use of ad hoc interpreters such as family members or untrained staff. Residents may be reluctant to document ad hoc interpreter use and, unlike professional interpreters at our institution who are trained to sign consent forms after they finish interpreting, ad hoc interpreters will not do so independent of a physician request. Ad hoc interpreter use is a common practice in the clinical care of LEP patients, and one that has been shown to result in decreased patient satisfaction, impaired communication, and potentially significant medical errors. ${ }^{24,25}$

Although the scenarios discussed may partially explain our findings, we believe that the low rates of documented interpreter use combined with fewer signed consent forms in the charts of LEP patients point to an alternate explanation: underuse of interpreters and hence inadequate or absent informed consent. This explanation is consistent with prior studies suggesting that residents underutilize interpreters when caring for LEP patients. ${ }^{12,17-19}$ In a survey of resident and attending physicians affiliated with this residency program, 66\% reported recent incidences in the outpatient setting in which they did not use an interpreter but wished they had. ${ }^{18}$ Previous training in interpreter use has been associated with increased use of professional interpreters, thus poor use of interpreters may be related at least in part to inadequate training of clinicians. ${ }^{18,24}$ In a recent national survey of medical residents, $35 \%$ reported no or very little instruction in delivering care through a medical interpreter, and only $51 \%$ reported receiving instruction in a patient's legal right to a medical interpreter. ${ }^{24}$ Getting by on limited language skills or with ad hoc interpreters for informed consent discussions is 
particularly problematic, as these conversations are often complex and require high-level language skills to ensure full comprehension on the part of the patient. More instruction on the appropriate use of professional interpreters is needed, as is research to understand the decision making and ultimately impact the practice of clinicians.

The process of informed consent requires attention and communication skills from physicians who often have multiple demands on their time. For patients who do not speak English, additional time and effort may be required to find a consent form in the patient's primary language, obtain the services of an interpreter, and ensure adequate understanding. Low literacy, which is common at public hospitals, ${ }^{26}$ has also been shown to complicate the process of informed consent. ${ }^{27,28}$ Yet providers have an ethical and legal obligation to provide informed consent for all patients, no matter how time consuming the process may be. Whereas it may present particular challenges, informed consent among vulnerable patient groups is critical to ensure patient safety and the provision of equitable, patient-centered health care. The National Quality Forum, a voluntary consensus standard-setting organization, recently endorsed improving informed consent for patients with limited health literacy or limited English proficiency as 1 of 30 evidence-based Safe Practices for Better Healthcare. ${ }^{29}$ This endorsement and similar initiatives by hospital accreditation groups may set the stage for ongoing quality monitoring, which is likely necessary to eliminate language disparities in informed consent.

Our study had several limitations. First, it was a study of documentation of informed consent, and the possibility of bias owing to differences in documentation requirements cannot be completely excluded. Second, it was a study at 1 teaching hospital and results may not generalize to other settings. However, our results may actually represent a "best case" scenario, as the setting is atypical in ways that would suggest better practice with LEP patients, including highly trained professional interpreters and residents accustomed to working with a large volume of LEP patients. Third, we studied 3 invasive bedside procedures performed by residents on hospitalized patients. Rates of informed consent may vary for different procedures performed by more seasoned physicians or in different settings. Fourth, the time of day of the procedure was not captured, and while the hospital has in-person interpreters available 16 hours a day and telephone interpreters available 24 hours a day, residents may have been less likely to document the involvement of telephone interpreters.

Despite these limitations, our study has several important implications. Informed consent is a fundamental tenet of the US health care system. It has long been legally recognized for its importance to the ethical practice of medicine, and it is increasingly being recognized as a key constituent of quality and patient safety. ${ }^{30}$ Ethnic disparities in informed consent are unacceptable and correctable. In response to our findings on documentation of informed consent, our institution has recommitted to providing resident physicians adequate instruction in the care of patients with limited English proficiency, the use of professional interpreters, and the process and documentation of informed consent. Other institutions may similarly wish to examine local practice and institute appropriate training. Meanwhile, hospitals and quality regulatory groups should consider adding informed consent for patients with limited English proficiency to their monitored measures of quality.
Acknowledgements: We gratefully acknowledge the advice and assistance of Robert Brody, MD, Andrew Brunner JD, Chris Elliot, Gloria Garcia-Orme, Jeffrey Kohlwes, MD, and Margaret Wheeler, $M D$, on this project.

Funding Sources: Dr. Fernandez's efforts were supported from NIH Career Development Award K23- RR018324-01. Ms. Wang was partially supported by HRSA grant D54HP03400.

Conflicts of Interest: None disclosed.

Corresponding Author: Alicia Fernandez, MD; Clinical Medicine, University of California, Box 1364, San Francisco, CA 94143, USA (e-mail: afernandez@medsfgh.ucsf.edu).

\section{REFERENCES}

1. President's commission for the study of ethical problems in medicine and biomedical and behavioral research. Making healthcare decisions: the ethical and legal implications of informed consent in the patientpractitioner relationship. New York; 1982 [cited 2006 Sept 15]. Available from: http://www.bioethics.gov/reports/past_commissions/index.html.

2. Stedman's Medical Dictionary, 27th Ed. Baltimore: Lippincott Williams \& Wilkins; 2000.

3. Rozovsky F. Consent to Treatment: A Practical Guide. 2nd Ed. Boston: Little, Brown and Company; 1990.

4. Beauchamp TL, Childress JF. Principles of Biomedical Ethics. 5th Ed. New York: Oxford University Press; 2001.

5. United States Census 2000. [cited 2006 Sept 15]. Available from: http:// www.census.gov/main/www/cen2000.html.

6. Chen A. Doctoring across the language divide. Health Aff. (Millwood). 2006;25:808-13.

7. Woloshin S, Schwartz LM, Katz SJ, Welch HG. Is language a barrier to the use of preventive services? J Gen Intern Med. 1997;12:472-7.

8. Baker DW, Hayes R, Fortier JP. Interpreter use and satisfaction with interpersonal aspects of care for Spanish-speaking patients. Med Care. 1998;36:1461-70.

9. Carrasquillo O, Orav EJ, Brennan TA, Burstin HR. Impact of language barriers on patient satisfaction in an emergency department. J Gen Intern Med. 1999;14:82-7.

10. Morales LS, Cunningham WE, Brown JA, Liu H, Hays RD. Are Latinos less satisfied with communication by health care providers? J Gen Intern Med. 1999;14:409-17.

11. Fernandez A, Schillinger D, Grumbach K, Rosenthal A, Stewart AL, Wang F, Perez-Stable EJ. Physician language ability and cultural competence. An exploratory study of communication with Spanishspeaking patients. J Gen Intern Med. 2004;19:167-74.

12. Baker DW, Parker RM, Williams MV, Coates WC, Pitkin K. Use and effectiveness of interpreters in an emergency department. JAMA. 1996;275:783-8.

13. Wilson E, Chen AH, Grumbach $\mathbf{K}$, Wang F, Fernandez A. Effects of limited English proficiency and physician language on health care comprehension. J Gen Intern Med. 2005;20:800-6.

14. Apter AJ, Reisine ST, Affleck G, Barrows E, ZuWallack RL. Adherence with twice-daily dosing of inhaled steroids. Socioeconomic and healthbelief differences. Am J Respir Crit Care Med. 1998;157:1810-17.

15. John-Baptiste A, Naglie G, Tomlinson G, et al. The effect of English language proficiency on length of stay and in-hospital mortality. J Gen Intern Med. 2004;19:221-8.

16. Grubbs V, Chen AH, Bindman AB, Vittinghoff E, Fernandez A. Effect of awareness of language law on language access in the health care setting. J Gen Intern Med. 2006;21:683-8.

17. Burbano O'Leary sc, Federico s, Hampers LC. The truth about language barriers: one residency program's experience. Pediatrics. 2003;111:e569-73.

18. Karliner LS, Perez-Stable EJ, Gildengorin G. The language divide. The importance of training in the use of interpreters for outpatient practice. J Gen Intern Med. 2004;19:175-83.

19. Yawman D, McIntosh S, Fernandez D, Auinger P, Allan M, Weitzman M. The use of Spanish by medical students and residents at one university hospital. Acad Med. 2006;81:468-73.

20. Written communication with Gloria Garcia-Orme, Director of Interpreter Services, San Francisco General Hospital. San Francisco. 2006.

21. San Francisco General Hospital Medical Center, Policy and Procedures. Consent to Medical and Surgical Procedures. Section 3.9. 2006. 
22. Executive Order 13166. Improving access to services for persons with limited English proficiency. The White House; August 11, 2000 [cited 2006 Sept 15]. Available from: http://www.usdoj.gov/.

23. Title VI of the 1964 U.S. Civil Rights Act, 42 U.S.C 200d. 1964 [cited 2006 Sept 15]. Available from: http://www.usdoj.gov/.

24. Lee KC, Winickoff JP, Kim MK, et al. Resident physicians' use of professional and nonprofessional interpreters: a national survey. JAMA. 2006;296: 1050-3.

25. Flores G. The impact of medical interpreter services on the quality of health care: a systematic review. Med Care Res Rev 2005;62:255-99.

26. Williams MV, Parker RM, Baker DW, Parikh NS, Pitkin K, Coates WC, Nurss JR. Inadequate functional health literacy among patients at two public hospitals. JAMA. 1995;274:1677-82.
27. Paasche-Orlow MK, Taylor HA, Brancati FL. Readability standards for informed-consent forms as compared with actual readability. N Engl J Med 2003;348:721-6.

28. Sudore RL, Landefeld CS, Williams BA, Barnes DE, Lindquist $\mathbf{K}$, Schillinger D. Use of a modified informed consent process among vulnerable patients: a descriptive study. J Gen Intern Med. 2006; 21:867-73.

29. National Quality Forum. Implementing a national voluntary consensus standard for informed consent. Washington, DC: National Quality Forum; 2005. Available from http://www.qualityforum.org.

30. Institute of Medicine (U.S.) Committee on Quality of Health Care in America. Crossing the Quality Chasm: A New Health System for the 21st Century. National Academy Press; 2001. 